\title{
InTERnational Policy Issues: OcEans
}

\author{
By Gunnar Kullenberg
}

$\mathrm{D}$ URING THE PRESENT DECADE, a number of international agreements have been negotiated that are related to the oceans and marine environment, either explicitly or inherently. Examples are the UN-FCCC (Framework Convention on Climate Change), the UN Convention on Biological Diversity, and the Global Programme of Action to protect the marine environment against Land Based Activities. In all these oceanography and ocean observations are very important elements, both with respect to the substantive basis and the rationale for agreement and its implementation. Furthermore, science and observations will have to play a major role in establishing the efficiency of the agreement to deal with the issue or the problem it is covering. In addition, the UN Convention on the Law of the Sea (UNCLOS) entered into force in November 1994.

In simplified terms, UNCLOS transfers major ocean resources to national management through the Exclusive Economic Zone (EEZ) and confirms the common heritage principle for management of the remaining parts of the ocean. This should be close to the principle of sustainable development, i.e., to meet the needs of the present without compromising the ability of future generations to meet their needs. The common heritage implies common responsibilities as well as benefits. Sustainable development requires data and knowledge about the ocean environment, its ability to sustain life, monitoring of changes, and ability to adequately forecast trends and changes over a range of time scales.

Other categories of international agreements are those dealing with coordinated. systematic ocean observations or

Gunnar Kullenberg. SC/IOC. UNESCO. 1 rue Miollis. 75015 Paris. France. research programs. These underpin efforts to enhance knowledge and data collection that are required inter alia for the negotiation and implementation of legal instruments. Examples of these are as follows: ocean observations, including regular ship-born observations, transmitted and registered in log books; buoy (fixed or drifting) observations; sea-level observations; regular voluntary ships observations now include physical, chemical, and biological parameters. Much of this is managed through specific international cooperation agreements such as IGOSS (Integrated Global Ocean Services System), DBCP (Data Buoy Cooperation Panel), CPR (Continuous Plankton Recording). GLOSS (Global Sea Level Observing System); International Mussel Watch; and Long-range Transport of Airborne Pollutants. One aim of the Global Ocean Observing System (GOOS) is to provide an integrating framework for all these efforts. and some of these observation networks are indeed part of the initial existing phase of GOOS.

The internationally coordinated and agreed research programs include the following: the World Ocean Circulation Experiment: the Joint Global Ocean Flux Study; the Land-ocean Interaction in the Coastal Zone Programme; and the Global Ocean Ecosystem Dynamics Programme. These programs are components of major international global change research efforts: the World Climate Research Programme (WCRP) and the International Geosphere-Biosphere Programme.

The joint IOC-UNEP-IMO-IAEA (Intergovernmental Oceanographic Commission-United Nations Environment Programme-International Maritime Organization-International Atomic Energy Agency) Global Investigation of Pollution in the Marine Environment (GIPME) is one example of a program producing practical results based on the involvement of the scientific community: methods and manuals published jointly through UNEP: training courses: intercalibration exercises; standards and reference materials: and coordination of the open ocean baseline study, the international mussel watch, river input studies. A base for the work is provided by the IAEA Marine Environment Laboratory in Monaco.

The results of the Tropical OceanGlobal Atmosphere (TOGA) experiment show very well that such efforts can deliver results. However, the uses of the results for the benefit of society as a whole are not covered by research or observation programs and obviously need to be ensured. Such a mechanism is not yet in place. The results of TOGA are applied in South America, e.g., Chile, Peru, and Brazil, in the context of planning and management of fresh water resources, agriculture, and fisheries. This involves several national agencies, and national pilot mechanisms have been put in place based on several user sectors.

There is a strong need to increase the linkage between science and management and the users and producers of scientific results. The scientific community needs to be involved with negotiations and implementations of legal instruments. such as those referred to above. It is only through science that forecasting of the ocean and coastal zone conditions can be achieved and scenarios or options for future development can be obtained. One mechanism that has been put in place for this purpose is the Intergovernmental Panel on Climate Change (IPCC) dealing with assessments of climate change. It has been able to deliver and is associated with the climate research community. However, it is not clear to what extent governments appreciate the very necessary contribution of the scientific community in providing the basis for legal instruments and the role of large-scale 
internationally organized and globally funded persistent research programs such as WCRP and its components. Neither has this mechanism convinced governments to ensure funding of the continuation of ocean observations established during TOGA at an adequate level to maintain forecasting ability, as well as to monitor variability. These activities should not be funded through research funds: new appropriations and resources must be found. This will require the identification of the users and a specification and quantification of the return the users would receive for the investment. Hence, there is a strong need to find economical expressions for scientific results and a mechanism to obtain them. The development of GOOS also addresses these matters. However, efforts such as TOGA as well as the World Ocean Circulation Experiment (WOCE) must underpin the development of GOOS.

Although knowledge and understanding of processes in the ocean have increased very considerably over the last decade, the existing data bases and systematic observations are insufficient for adequate management. Forecasts of changes in coastal zones cannot be made with sufficient adequacy for economic management. A dialogue needs to be established between management. fact-finders, and forecasters, and management needs to be informed of the availability of new tools. A mechanism must include an adequate means to achieve proper dialogue between the research community and policy makers so that the research results can be fully utilized by policymakers for the benefit of society at large, and real research, including related observations and experiments, can be properly funded.

Mechanisms are emerging to deal with ocean issues at the regional level. These are in a few cases intersectoral and include research and observations. The regional perspective appears promising since common interests can be identified and joint actions agreed upon. Regional cooperation also includes aspects related to stability and security. The participating nations can obtain direct benefits, and the characteristics of the particular part of the ocean and marine environment can be taken into account in management. Mechanisms to obtain sustained support for research as well as systematic observations may be obtained from common user communities. The need for adequate scientific inputs are well identified.

One major gap is the lack of an integrating forum or platform where all the different interests including the private sector, institutions, organizations, nongovernmental organizations and governmental organizations, and conventions covering various aspects of ocean issues can establish a dialogue that can respond to a joint policy shaping need where commitments can be made and implementation agreements reached. Such a forum could perhaps be achieved as part of the United Nations General Assembly if a dedicated time period on a regular basis could be set aside for debating ocean issues.

Experience has shown that success is obtained where there are major user interests involved and where the activities are user-driven. However, integration is not usually achieved. and results in one sector are often not really transferred for application to other sectors. The reasons for this can be lack of information and lack of communication. Hence, a forum will require that all users and sectors can participate. To achieve implementation of agreements and programs, the mechanism must have sufficient political status. None of the existing mechanisms have that individually; perhaps they could have it jointly if working through a joint forum. This will. however. require leadership and the ability to agree on priorities that now appear to emerge in the form of major issues, although the mechanisms to address them seem to lead to further sectoralization.

Society-related ocean issues are relatively well identified: oceans and climate and impacts of changes; protection of coastal areas; ocean resources for food. energy, production of minerals and other materials and related security; ocean (coastal zones) pollution; and role of the ocean in the hydrological cycle. For some issues to be addressed properly, adequate management is required of society's actions on land, e.g., for land-based sources of marine pollution. Collection of data and information together with their interpretation and application to analyze and make assessments are or should be initial parts of most actions aiming at the protection and management of the marine environ- ment. These steps are scientific and factual. The scientific community has a large role to play in these actions. It is necessary to enter and take up the responsibility. In several cases, scientific research has provided or is coming close to providing solutions, forecasting abilities and options for societal actions regarding management. However, there is no satisfactory mechanism available to ensure that these results are applied. It must be emphasized that science is necessary to obtain solutions that address the issues. It appears, however, that in order to attract the attention of the public and policymakers there must be a visible link to the benefit in economic terms of an action. Increased communication and dialogue is required between the community that knows about the marine environmental problems in depth and the public at large. At the present time, focus is given to the coastal zone. However, we have a duty to point out the need to address larger issues that need a wider ocean focus. Governments must act in concert at the regional and global levels to address ocean problems. Adequate regional and global intergovernmental mechanisms must be in place to ensure compatibility of actions, and coordination and to provide a forum where agreements on joint coordinated actions can be reached. As regards marine research, ocean observations and related capacity building, the IOC. and its regional subsidiary bodies provide for such mechanisms. Through these mechanisms a sharing of knowledge and scientific methods can be achieved. However, the mechanisms must be adequate and need appropriate strengthening.

Efforts are underway in the United Nations framework and outside to restructure existing intergovernmental machinery and put in place an appropriate forum to address ocean issues with proper linkages to the interaction between the oceans and other parts of our planet. The 1998 International Year of the Ocean may be used to obtain commitments from governments and other sectors of society. The IOC is endeavoring to inject the need to cater to ocean research and observations in partnership with the International Council of Scientific Unions (ICSU). Support is required from the scientific community, and I cordially invite you to provide your input in accordance with your values, needs, and experiences. $\square$ 